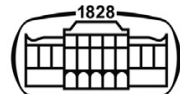

AKADÉMIAI KIADÓ

European Journal of Microbiology and Immunology

11 (2021) 3, 62-75

DOI:

$10.1556 / 1886.2021 .00011$

(c) 2021 The Author(s)

\section{ORIGINAL RESEARCH} PAPER

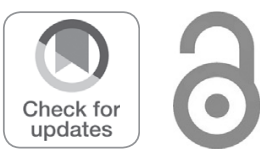

\title{
Real time micro-organisms PCR in 104 patients with polymorphic signs and symptoms that may be related to a tick bite
}

\author{
ALEXIS LACOUT $^{1 *} \odot$, MARIE MAS ${ }^{2}$, JULIE PAJAUD ${ }^{3}$, \\ VÉRONIQUE PERRONNE ${ }^{4}$, YANNICK LEQUETTE ${ }^{3}$, \\ MICHEL FRANCK ${ }^{3}$ and CHRISTIAN PERRONNE ${ }^{4}$
}

\footnotetext{
${ }^{1}$ Centre de Diagnostic ELSAN, Centre Médico-Chirurgical, 83 Avenue Charles de Gaulle, 15000, Aurillac, France

${ }^{2}$ Clinique Convert, Médecine Générale, Service des Urgences, 62 Avenue de Jasseron, 01000, Bourg en Bresse, France

${ }^{3}$ ADNucleis, 3 Route des Pierres Blanches, 69290, Grézieu la Varenne, France

${ }^{4}$ Hôpital Universitaire Raymond Poincaré (Assistance Publique - Hôpitaux de Paris), Département d'Infectiologie, Université de Versailles - Saint Quentin, Paris-Saclay, France
}

Received: June 20, 2021 • Accepted: October 6, 2021

Published online: November 3, 2021

\begin{abstract}
Introduction: Ticks are frequently polyinfected and can thus transmit numerous microorganisms. A large number of bacteria, parasites and viruses are transmitted by tick bites and could cause different signs and symptoms in patients. The main goal of this study was to search for these numerous microorganisms in patients presenting with persistent polymorphic syndrome possibly due to a tick bite (SPPT). Patients and methods: The following microorganisms were searched for in saliva, urine, venous and capillary blood by using real time PCR: Borrelia burgdorferi sensu lato, Borrelia miyamotoi, Borrelia hermsii, Bartonella spp., Bartonella quintana, Bartonella henselae, Ehrlichia spp., Anaplasma spp., Rickettsia spp., Coxiella burnetii, Brucella spp., Francisella tularensis, Mycoplasma spp., Chlamydia spp., Babesia spp., Theileria spp. Results: 104 patients were included. $48 \%$ of the patients were poly-infected, and $25 \%$ harboured at least three different microorganisms. Borrelia spp. were not the most frequent bacteria observed, observed far behind Mycoplasma spp., Rickettsia spp. and Ehrlichia spp. which were the most frequent microorganisms observed. Piroplasms were found in a significant number of patients. The most sensitive matrix was saliva, followed by urine, capillary blood and venous blood. Conclusion: Our prospective study has shown that patients with SPPT, a syndrome close to fibromyalgia, could harbour several tick borne microorganisms.
\end{abstract}

\section{KEYWORDS}

lyme, Borrelia, Babesia, PCR, PTLDS, SPPT, capillary blood, saliva

\section{INTRODUCTION}

Lyme disease is a tick-borne infectious disease caused by Borrelia burgdorferi sensu lato (including B. burgdorferi sensu stricto, Borrelia afzelii and B. Garinii). The prevalence seems to be increasing in many countries around the world, particularly in France. In addition, some experts make the assumption that Lyme disease is not the only factor to explain the persistent polymorphic syndrome possibly due to a tick bite (SPPT), a syndrome close to the post-treatment Lyme disease syndrome (PTLDS) [1]. A large number of bacteria (other than Borrelia), parasites and viruses are transmitted by tick bites and could cause different signs and symptoms in patients, the so-called co-infections. In addition, the efficiency of Lyme serology is controversial with a tough scientific debate and it seems that the recommended
* Corresponding author. Tel.: +33 687273707; fax: +33 471485348 E-mail: lacout.alexis@icloud.com 
two-tier testing for antibody detection (ELISA test followed, if positive, by a Western blot test) lacks sensitivity [2-8]. Above all, this serology only looks for some species of Borrelia. Another controversial issue is the persistence of the bacterium after antibiotic treatment.

Indeed ticks are frequently polyinfected and can transmit numerous microorganisms [9-12], whether bacteria (other species of Borrelia, Bartonella spp., Ehrlichia spp., Rickettsia spp....), viruses, or parasites, first and foremost piroplasms (Babesia). Lyme disease is due to B. burgdorferi sensu lato, other species of Borrelia are responsible for relapsing fevers (transmitted by ticks or lice according to the species. Borrelia miyamotoi is now found in symptomatic patients, either with acute or chronic disease [13, 14]. The best known species of Bartonella are Bartonella henselae, responsible for cat scratch disease and Bartonella quintana, transmitted by lice and the agent of trench fever. They are usually investigated by serology [15-17]. In fact, there are many other species of Bartonella which may be transmitted by ticks and may cause neurological damage: radiculitis, myelitis, neurocognitive disorders for example. Bartonella have also been identified from patients with psychiatric diseases [17].

Other species of Borrelia, known in veterinary medicine has been found in the blood of patients with chronic syndromes [18]. Ehrlichia are responsible for ehrlichiosis, a tickborne disease, which may be a Lyme disease co-infection [19]. Rickettsia species are numerous and are responsible for different groups of diseases, such as spotted fevers and typhus. Piroplasms are tick-borne monocellular parasites infecting red blood cells. Piroplasms include Babesia and Theileria species. Babesiosis is mainly known as an acute severe disease in splenectomised or deeply immunosuppressed persons, but the chronic form of the disease has not been much studied and is not well known. At the present time, Theileria have been only identified in animals, mainly horses. In the literature, no formal correlation between the isolation of such various micro-organisms and persistent signs and symptoms could be established.

Thus, the main goal of this study was to look for the different microorganisms transmitted or not by ticks in patients suffering from polymorphic signs and symptoms (SPPT/PTLDS), using real time qPCR, which is a direct diagnostic method amplifying the DNA of the microorganisms sought. As the yield of PCRs looking for Borrelia or co-infections in the venous blood is low [20, 21], another aim was to compare the results obtained by quantitative real time polymerase chain reaction (real time qPCR) from several matrices (venous blood, urine, saliva and capillary blood). The last aim was to evaluate the relevance to draw two samples, at Day 0 and Day 2.

\section{PATIENTS AND METHODS}

This is a prospective multi-centre observational study associating 8 clinical centres and one laboratory performing PCR analyses (AdNucleis) including patients with persistent polymorphic syndrome possibly due to a tick bite (SPPT).
SPPT is a syndrome officially recognized by the French High Authority for Health (HAS) (a governmental institution https://www.has-sante.fr). SPPT includes post-treatment Lyme disease syndrome (PTLDS), but also addresses other hidden infections (crypto-infections).

SPPT is defined by a clinical triad associating several times a week, for more than 6 months: a polyalgic syndrome (musculoskeletal pain and/or neuropathic pain and/or headaches); persistent fatigue with reduced physical capacities; cognitive complaints. The difference between SPPT and PTLDS is that a diagnosis of Lyme disease has not to be proven and patients may have not been treated [22, 23].

\section{Patients}

The criteria for inclusion in this prospective study were: SPPT patients of at least 18 years of age, of either sex, presenting with the following signs or symptoms evolving for more than 6 months:

1. Neurocognitive disorders.

2. More than 2 of the following chronic sign or symptom categories:

- Musculoskeletal: muscle pain, arthritis or arthralgia;

- Neurological: facial paralysis, central or peripheral involvement, myelitis, root pain, paresthesias, dysesthesias, radiculopathy.

3. Abnormal asthenia.

4. Lack of etiology.

5. Have given their signed informed consent.

The following patients were excluded from the study:

1. Patients under 18 years of age, a context of acute intercurrent infectious pathology.

2. Patients who had received prior systemic antibiotic or antiparasitic treatment within two months prior to blood collection.

The protocol was approved by the ethical committee (Comité de protection des personnes CPP SUD EST VI Clermont Ferrand, France; document number: Ref. CPP AU 1396 Ref. ID-RCB 2017-A02705-48). All patients and control persons signed an informed consent in accordance with the Declaration of Helsinki.

\section{Microorganisms searched}

The following microorganisms were searched for by using real time PCR (Tables 1 and 2): B. burgdorferi sensu lato (s.l.), B. afzelii, B. miyamotoi, Borrelia hermsii, Bartonella spp., B. quintana, B. henselae, Ehrlichia spp., Anaplasma spp., Rickettsia spp., Coxiella burnetii, Brucella spp., Francisella tularensis, Mycoplasma spp., Chlamydia spp., Babesia spp., Theileria spp. Theileria spp. was investigated only at the end of the study for 33 patients.

Sample collection and nucleic acid sample preparation. Five $\mathrm{ml}$ of blood were collected by venous puncture in tubes with EDTA as anti-coagulant, capillary blood from the tip 
Table 1. Real Time Multiplex polymerase chain reaction (PCR)

Samples

Selection of Primers

Robustness of PCR Mixes

DNA Extraction and Purification

Control of the Extraction

Real-Time PCR (real time PCR)

Quantification
Urine and saliva were collected in dry bottles, five milliliters of blood were collected by venous puncture and around $500 \mu \mathrm{l}$ of capillary blood were collected by finger prick in tubes with EDTA as anti-coagulant, before any antibiotic treatment and were sent in Vacutainer ${ }^{\circledR} \mathrm{K} 2$ tubes.

Samples (venous blood, urine, saliva, capillary blood) were drawn twice at Day 0 (D0) and Day 2 (D2).

To allow the detection of bacteria and parasites, primers targeting specific genes of each microorganism were used to amplify DNA by qPCR. Details of qPCR kits used is listed in Table 2. The portion of target genes were synthesized and introduced into a plasmid to obtain a control DNA and facilitate its multiplication. This control DNA was used to validate the amplification mixes. Serial dilution of the plasmid was performed and amplified to determine the robustness parameters of each PCR kit: the limit of detection (LOD), the limit of quantification (LOQ), the repeatability and the reproducibility.

The DNA was extracted without any prior treatment using $300 \mu \mathrm{l}$ of whole blood with an equal volume of ADNucleis extraction buffer ( $5 \mathrm{M}$ guanidium thiocyanate, $500 \mathrm{mM}$ TrisHCL, $50 \mathrm{mM}$ EDTA, 20\% Tween 20, 20\% Triton X-100, $750 \mu$ g proteinase K). After incubation for 20 min at $56^{\circ} \mathrm{C}$ and $15 \mathrm{~min}$ at $80^{\circ} \mathrm{C}$, the extracted DNA was purified by means of silica magnetic beads and eluted in $250 \mu \mathrm{l}$ of elution buffer (10 mM TrisHCl, $\mathrm{pH} 8.5)$.

Human glyceraldehyde-3-phosphate dehydrogenase (hGAPDH) was used as a housekeeping gene as an internal control for PCR extraction and inhibition. The extracted samples were first checked with a PCR targeting the GAPDH gene. If the results of this PCR were consistent (Ct of GAPDH below 32), the samples were then analyzed for the other pathogens. The sequence of interest of GAPDH was inserted into a plasmid and this plasmid was used as a positive DNA for the validation of GAPDH primers and PCR mix as well as a positive control for subsequent PCRs. The primers used for GAPDH are described in Table 2.

Real-time PCR was carried out in a total volume of $50 \mu \mathrm{l}$ with a PCR mix containing ADNucleis PCR buffer (20 mM Tris- $\mathrm{HCl}, 10 \mathrm{mM} \mathrm{NH}_{4} \mathrm{SO}_{4}, 10 \mathrm{mM} \mathrm{KCl}, 2 \mathrm{mM} \mathrm{Mg} 2+, 0.1 \%$ TritonX-100, $\mathrm{pH} 8.8$ ),

$2 \mathrm{mM}$ of each dNTP, $600 \mathrm{nM}$ of each primer, $1 \mu \mathrm{l}$ of Evagreen and 5 units of Taq polymerase ADNucleis. Twelve $\mu$ l of extracted samples were amplified.

An initial denaturation step of $5 \mathrm{~min}$ at $95^{\circ} \mathrm{C}$ was followed by 42 cycles of $15 \mathrm{~s}$ at $95^{\circ} \mathrm{C}$ and $40 \mathrm{~s}$ at $60^{\circ} \mathrm{C}$

(hybridization-elongation). The dissociation curves were generated by a last step of $10 \mathrm{~min}$ with temperature increments from 75 to $95^{\circ} \mathrm{C}$ for qPCR kits using Sybr green technology.

Positive samples were quantified using a standard curve obtained by amplifying known and calibrated concentrations of control DNA of the desired targets. Quantification was obtained using the standard curve equation $(\mathrm{Ct}=\mathrm{a}(\log 10[\mathrm{DNA}])+\mathrm{b})$ where "a" is the slope and " $\mathrm{b}$ " the intercept of the curve. The results were expressed in genome units (UG) per ml of sample.

LOD: limit of detection.

LOQ: limit of quantification.

UG: Genome Units.

Ct: Cycle threshold.

LOD limit of detection and LOQ limit of quantification.

The LOD is calculated by comparing the response of the PCR kit with respect to a reference method, which is most often a method for cultivating the microbial population.

Once this microbial population has been cultured, it is stopped when the population is most abundant (eg 10E9); a count is carried out and the microbial population is subjected to successive dilutions in order to be able to have samples from 10E9 to 0, passing through all the intermediates (10E8, 10E7, etc.); these samples constitute the reference and the Borrelia analysis kit is evaluated for each dilution; we look for the sensitivities of the PCR kits making it possible to detect at least 10E2 DNA copies/PCR reaction volume, at best 10 copies/PCR reaction volume or less.

LOD is therefore expressed in DNA copies (or RNA for most viruses) detected per PCR reaction volume; and when we evaluate the regression of the response of the kit (in Ct with respect to each dilution) we must obtain a straight line of which we evaluate the linearity (equation) and the slope (a of the equation $y=\mathrm{ax}+b$, y being the log value of the concentration of the bacterial population, $x$ the value of the response of the kit in $\mathrm{Ct}$ ); most often, this linearity is not complete, in particular for low concentrations of the microbial population; Then comes the LOQ (limit of quantification) which is the lowest detection value evaluated on the linear part of the regression line. The LOQ is therefore always greater than the LOD, if the latter is of the order of 5 copies/PCR reaction volume, the LOQ can be between 40 and 100 copies/PCR reaction volume; these values are always carefully assessed by the manufacturer before placing the PCR reaction kit on the market.

of the fingers was collected in tubes with EDTA, urine was collected in sterile bottle and saliva was collected using swab. $300 \mu \mathrm{l}$ of venous and capillary blood were used to extract nucleic acid. $10 \mathrm{ml}$ of urine were first centrifuged $10 \mathrm{~min}$ at $4,500 \mathrm{rpm}$ in swinging bucket rotor, then the supernatant was discarded, and the pellet was resuspended in $300 \mu \mathrm{l}$ of Rnase Dnase free water. Saliva swab sample was resuspended in $1 \mathrm{ml}$ of Tris $\mathrm{HCl} 10 \mathrm{mM}$ EDTA $1 \mathrm{mM}$ buffer. $300 \mu \mathrm{l}$ of the resuspension was used to extract nucleic acid. 
Table 2. List of desired targets and details of PCR kits

\begin{tabular}{|c|c|c|c|c|c|c|c|c|c|}
\hline Microorganisms & Species & Genes/name & Technology & Primers $\mathrm{F}$ & Primers $\mathrm{R}$ & Probe & $\begin{array}{l}\text { Taqman } \\
\text { Dye/Tm } \\
{ }^{\circ} \mathrm{C} \text { Sybr }\end{array}$ & $\begin{array}{l}\text { LOD } \\
\text { (UG/ } \\
\text { PCR) }\end{array}$ & $\begin{array}{l}\text { LOQ } \\
\text { (UG/ } \\
\text { PCR) }\end{array}$ \\
\hline $\begin{array}{l}\text { Borrelia } \\
\text { burgdorferi }\end{array}$ & sensu lato & Flagelline & Tqm & CAAAYCAAGATGAAGCDATTGCWGTA & CTTCYTSTTGARCWCCYTCTTGAA & TGCAGYCTGAGCAGYYTGAGCT & FAM & 5.7 & 2280 \\
\hline Borrelia & miyamotoi & glpQ & Sybr & TGCACAATTATTTCCCAATCGA & TTCACTGAGACTTAGTGATTTAAGTTCAGTT & & $80^{\circ} \mathrm{C}$ & 12.5 & 18.8 \\
\hline Borrelia & hermsii & flaB & Sybr & AGCTGGATCACAAGCTTCATGGACA & СССТCTATCTTTGCAAGTGACA & & $87^{\circ} \mathrm{C}$ & 12.5 & 125 \\
\hline Borrelia & afzelii & СР009058.1 & Sybr & AATTGCTTGTAGAGTTAA & AAGTTGCTGTTAGTATAG & & & 63.6 & 636.2 \\
\hline Bartonella & spp. & rpoB & Sybr & CARGATTTRATTAAYGCRAA & ACRTCRCGMACTTCAAAR & & $87^{\circ} \mathrm{C}$ & 2.57 & 12.8 \\
\hline Bartonella & henselae & ribC & Sybr & GATATCGGTTGTGTTGAAGA & AATAAAAGGTATAAAACGCT & & $84^{\circ} \mathrm{C}$ & 19 & 125 \\
\hline Bartonella & quintana & ribE & Sybr & GATATCGGTTGTGTTGAAGA & AAAGGGCGTGAATTTTG & & $84^{\circ} \mathrm{C}$ & 2.5 & 125 \\
\hline Babesia & spp. & $18 \mathrm{~S}$ & Sybr & ACCTGCTAACTAGTDBCC & CACAGACCTGTTATTGCC & & $84^{\circ} \mathrm{C}$ & 5.7 & 5.7 \\
\hline Rickettsia & spp. & $\begin{array}{c}\text { ARN 23S } \\
\text { NR_076610.1 }\end{array}$ & Sybr & ACCGATAGTGAACAAGTA & GGGTCTAATTYATCTAACTAAA & & $85^{\circ} \mathrm{C}$ & 35.6 & 1780 \\
\hline Ehrlichia & spp. & $16 \mathrm{~S}$ & Sybr & GAGGATTTTATCTTTGTATTGTAGCTAAC & TGTAAGGTCCAGCCGAACTGACT & & $85^{\circ} \mathrm{C}$ & 6 & 6 \\
\hline Anaplasma & spp. & Gène MSP4 & Sybr & TTGTTTACAGGGGGCCTGTC & CTTGCCTAGCCTCTAACGTATGAG & & $85^{\circ} \mathrm{C}$ & 25 & 25 \\
\hline Coxiella & burnetii & is111a & Tqm & AATTTCATCGTTCCCGGCAG & GCCGCGTTTACTAATCCCCA & TGTCGGCGTTTATTGGGTTGGTCCC & FAM & 2.28 & 114 \\
\hline Mycoplasma & spp. & ARN 16S & Tqm & CACACTGGGACTGAGATA & TTCGCCCATTGTGGAATA & CCCTACTGCTGCCTCCCGTA & FAM & 5.65 & 283 \\
\hline Brucella & spp. & IS711 & Sybr & CAATCTCGGAACTGGCCATCTCGAACGGTAT & ATGTTATAGATGAGGTCGTCCGGCTGCTTGG & & $88^{\circ} \mathrm{C}$ & 48.4 & 48.4 \\
\hline Francisella & tularensis & fopA & Tqm & AACAATGGCACCTAGTAATATTTCTGG & CCACCAAAGAACCATGTTAAACC & TGGCAGAGCGGGTACTAACATGATTGGT & FAM & 11.4 & 114 \\
\hline Theileria & spp. & ARN $18 \mathrm{~S}$ & Tqm & ACCTCTTCCAGAGTATCA & GCAGAAATTCAACTACGAG & CAAGTCTGGTGCCAGCAGCC & FAM & 11.7 & 1170 \\
\hline Chlamydia & spp. & $16 \mathrm{~S}$ & Tqm & TGGCTCTCATGCAAAAGGCA & GATGCCTGGCATTGATAGGCGAWGAAGGA & TGGTTTCAGGTTCTATTTCACTCCC & FAM & 48.4 & 484 \\
\hline hGAPDH & & hGAPDH & Tqm & GAAGGTGAAGGTCGGAGT & GAAGATGGTGATGGGATTTC & CAAGCTTCCCGTTCTCAGCC & FAM & 22.8 & 227.9 \\
\hline
\end{tabular}

Tqm: Taqman.

Sybr: Syber Green fluorophore.

The choice of the PCR technique (Sybr green or Taqman) is essentially linked to the sensitivity of each of the techniques; contrary to what is usually said, the two techniques are roughly equivalent, one being better than the other for certain targets and vice versa. And since we are looking for the best sensitivity in all cases, the laboratory has kept both techniques. FAM: 6-carboxyfluorescéine (fluorophore)

LOD: limit of detection.

LOQ: limit of quantification.

UG: Genome Units.

The sensitivity of each kit, in particular the limit of detection (LOD) and the limit of quantification (LOQ), are the subject of an analytical evaluation calculated according to the recommendations of Regulation (EU) 2017/746

LOD limit of detection and LOQ limit of quantification.

The LOD is calculated by comparing the response of the PCR kit with respect to a reference method, which is most often a method for cultivating the microbial population.

Once this microbial population has been cultured, it is stopped when the population is most abundant (eg 10E9); a count is carried out and the microbial population is subjected to successive dilutions in order to be able to have samples from $10 \mathrm{E} 9$ to 0 , passing through all the intermediates (10E8, 10E7, etc.); these samples constitute the reference and the analysis kit is evaluated for each dilution; we look for the sensitivities of the PCR kits making it possible to detect at least 10E2 DNA copies or genome unit (UG)/PCR reaction volume, at best 10 copies/PCR reaction volume or less.

LOD is therefore expressed in DNA copies (Genome Units UG) detected per PCR reaction volume; and when we evaluate the regression of the response of the kit (in Ct with respect to each dilution) we must obtain a straight line of which we evaluate the linearity (equation) and the slope (a of the equation $y=a x+b$, y being the log value of the concentration of the bacterial population, $x$ the value of the response of the kit in Ct); most often, this linearity is not complete, in particular for low concentrations of the microbial population; Then comes the LOQ (limit of quantification) which is the lowest detection value evaluated on the linear part of the regression line. The LOQ is therefore always greater than the LOD, if the latter is of the order of 5 copies/ PCR reaction volume, the LOQ can be between 40 and 100 copies/PCR reaction volume; these values are always carefully assessed by the manufacturer before placing the PCR reaction kit on the market. 
The ADNucleis DNA extraction-purification bead kit (ref ADNPVG300+BM) was used to extract DNA directly from $300 \mu \mathrm{l}$ of blood samples or from processed sample as described above (urine and saliva).

Real time PCR method. Control DNA plasmids containing the amplified fragment was constructed to validate the amplification mixes, to be used as positive control. Serial dilution of the plasmid from 1-10 copies/PCR to $10^{8}$ copies/ PCR was made and used to determine the limit of detection (LOD), the limit of quantification (LOQ) of each target, Tm for the Sybr mixes (listed in Table 2). The primer and probes are listed in Table 2. Primes and probes were from the literature or designed for this study. Each target was tested as individual monoplex. The real time PCR was performed using TaqMan or 'SYBR' technologies. Each mixes were validated with specific PCR components used and developed by ADNucleis (including the Taq polymerase). The thermal cycling conditions of rt PCR were as following: $95^{\circ} \mathrm{C} 5 \mathrm{~min}, 42$ cycles of $95^{\circ} \mathrm{C} 10$ s and $60^{\circ} \mathrm{C} 40$ s for the TaqMan rt PCR. The EvaGreen PCR thermal cycling condition were the same the TaqMan one, expect the addition of the melting curve step $\left(95^{\circ} \mathrm{C} 15 \mathrm{~s}, 75^{\circ} \mathrm{C} 15 \mathrm{~s}\right.$ increasing temperature to $95^{\circ} \mathrm{C}$ and $\left.95^{\circ} \mathrm{C} 15 \mathrm{~s}\right)$. The reaction volume was 40 and $12 \mu \mathrm{l}$ of DNA samples. A Ct cycle thermic (Ct) higher than 38 was considered as negative for the TaqMan mixes. A Tm within the range $\mathrm{TM}+/-1{ }^{\circ} \mathrm{C}$ was considered positive for the EvaGreen mixes. Each mixes were validated with specific PCR components used and developed by AD Nucleis (including the Taq polymerase).

\section{Ethics statement}

The study has been approved by an appropriate ethics committee and have therefore been performed in accordance with the ethical standards laid down in the 1964 Declaration of Helsinki and its later amendments. National laws have been observed. The protocol was approved by the ethical committee (Comite de protection des personnes CPP SUD EST VI Clermont Ferrand, France; document number: Ref. CPP AU 1396 Ref. ID-RCB 2017-A02705-48).

\section{RESULTS}

\section{Lack of detection of micro-organisms in healthy persons using venous blood qPCR}

In a group of 24 healthy asymptomatic students, $B$. burgdorferi s.l., B. miyamotoi, Ehrlichia spp., Babesia spp., $B$. hermsii, B. henselae, B. quintana were searched by PCR in venous blood. All the PCR results were negative (Table 3).

\section{PCR and patients}

In this study, 109 patients were included. For five patients, samples were analyzed at D0 only, and for 104 patients, samples were analyzed at D0 and D2. Venous blood was explored in 97 patients, urine and saliva in 104 patients. In addition to these three matrices, capillary blood was
Table 3. Lack of detection of micro-organisms in the healthy persons in venous blood qPCR

Borrelia burgdorferi s.l., Borrelia miyamotoi, Ehrlichia spp., Babesia spp., Borrelia hermsii, Bartonella henselae, Bartonella quintana, were searched by qPCR on a control group of 24 healthy asymptomatic students. For all extracted blood samples, a Ct of less than 32 was detected for the GAPDH extraction control. All the PCR results were negative.

\begin{tabular}{lccr}
\hline & $\begin{array}{c}\text { PCR } \\
\text { Inhibition }\end{array}$ & $\begin{array}{c}\text { Ct GAPDH } \\
\text { values }\end{array}$ & Detection \\
\hline FDC071 & No & 29.44 & Not Detected \\
MCM072 & No & 24.46 & Not Detected \\
MGA073 & No & 28.57 & Not Detected \\
MFA074 & No & 28.47 & Not Detected \\
FBF075 & No & 27.7 & Not Detected \\
MDW076 & No & 27.76 & Not Detected \\
FDT077 & No & 30.97 & Not Detected \\
MAJ078 & No & 28.29 & Not Detected \\
MMC079 & No & 28.81 & Not Detected \\
FMS081 & No & 28.08 & Not Detected \\
MSL082 & No & 31.28 & Not Detected \\
MMD085 & No & 31.55 & Not Detected \\
MPA088 & No & 30.57 & Not Detected \\
FVA089 & No & 29.98 & Not Detected \\
MGW092 & No & 31.17 & Not Detected \\
FDN093 & No & 29.15 & Not Detected \\
MBA094 & No & 31.87 & Not Detected \\
FFS095 & No & 28.32 & Not Detected \\
FBA096 & No & 28.7 & Not Detected \\
FGA098 & No & 28.89 & Not Detected \\
MACA101 & No & 26.54 & Not Detected \\
MLS103 & No & 30.83 & Not Detected \\
FLH105 & No & 31.77 & Not Detected \\
FLL106 & No & 28.44 & Not Detected \\
Positive control & No & 22.83 & Detected \\
Negative control & No & 0 & Not Detected \\
\hline
\end{tabular}

explored in 65 patients. A total of 730 samples were analyzed. Among them, 366 PCRs (50.1\%) were positive.

Theileria spp., a parasite close to Babesia spp., was investigated in only 33 patients, because this research having been added late in the course of the study. Thus, the results are presented separately.

\section{Real time Qpcr at day 0 (D0) and day 2 (D2)}

No microorganisms were found in $5(4.8 \%)$ patients. Ninetynine patients out of $104(95.2 \%)$ were positive for a least one microorganism (Figs 1-5) (Table 4), 47 (45.2\%) patients were positive for at least one microorganism excluding Mycoplasma spp. The most frequent bacteria found were $\mathrm{Myco-}$ plasma spp., following by Rickettsia spp. and Ehrlichia spp. For two bacterial genera, Borrelia and Bartonella, several species of the same genus were identified. Five PCRs (1 at D0 and 4 at D2) in 4 patients (3.85\%) were positive for Borrelia: 2 (1 at D0 and 1 at D2) in 1 patient $(0.96 \%)$ for B. afzelii, 1 ( 1 at D0 and 0 at D2) in 1 patient (0.96\%) for B. miyamotoi, 2 (0 to D0 and 2 to D2) in 2 patients (1.92\%) for B. hermsii.

Twenty-three PCRs (14 at D0 and 9 at D2) in 16 patients (15.38\%) were positive for Bartonella, 5 (4 at D0 and 1 at D2) 


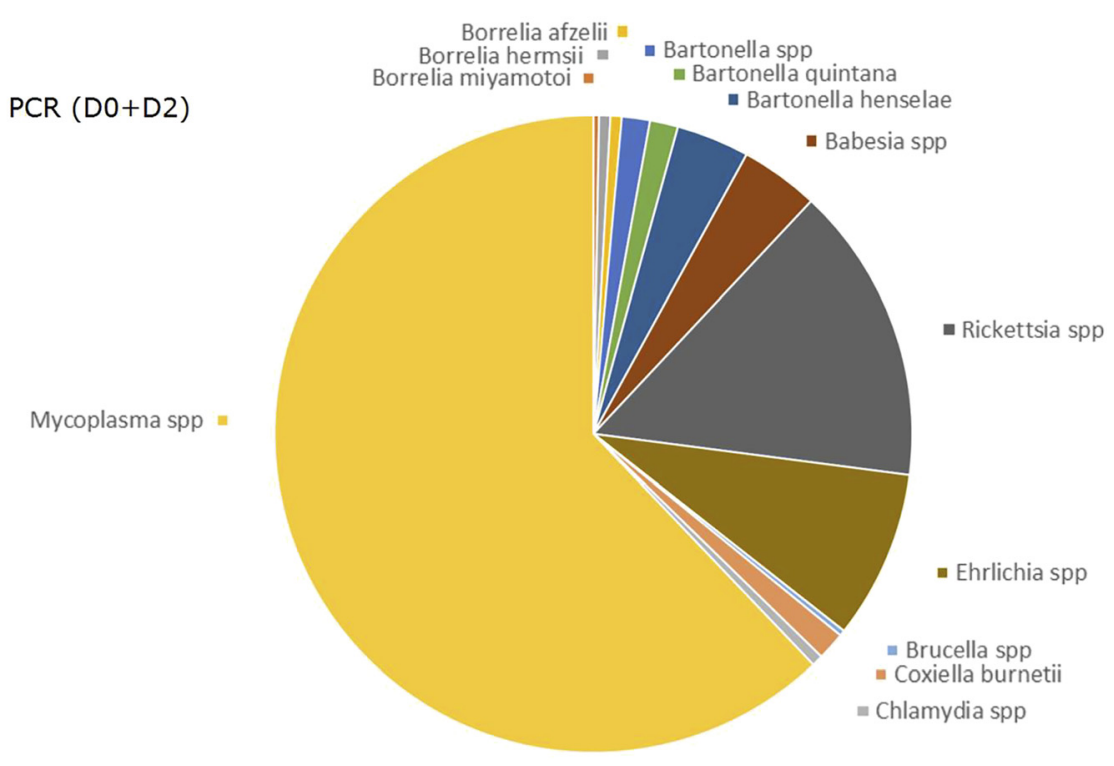

Fig. 1. PCR results at D0 $+\mathrm{D} 2$

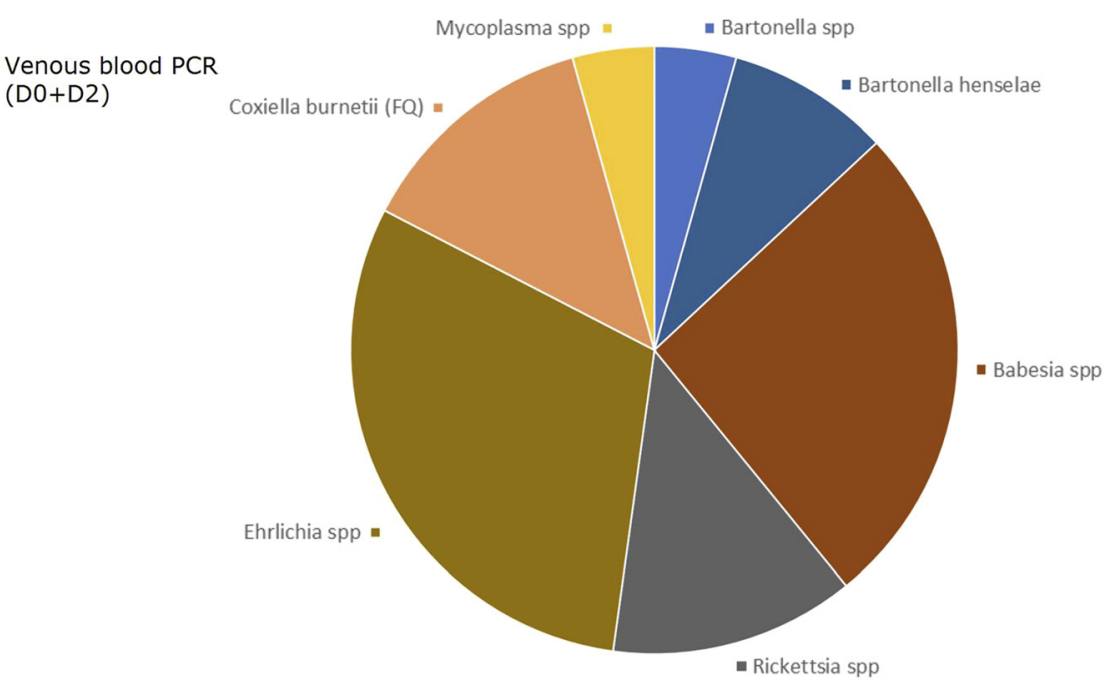

Fig. 2. Venous blood PCR results at D0 + D2

in 4 patients $(3.85 \%)$ for B. quintana, 13 (7 at D0 and 6 at D2) in 4 patients (3.85\%) for B. henselae, and 5 (3 at D0 and 2 at D2) in 8 patients (7.7\%) for other Bartonella spp.

14 PCRs (6 at D0 and 8 at D2) in 9 patients $(8.65 \%)$ were positive for Babesia spp.

53 PCRs (30 at D0 and 23 at D2), in 31 patients (29.8\%) were positive for Rickettsia spp.

5 PCRs ( 3 at D0 and 2 at D2), 3 patients (2.88\%) were positive for Coxiella burnetii.

30 PCRs (15 at D0 and 15 at D2), 15 patients (14.42\%) were positive for Ehrlichia spp.

1 PCR (0 to D0 and 1 at D2), in 1 patient (0.96\%) was positive for Brucella spp.

2 PCRs (0 to D0 and 2 at D2), 2 patients (1.92\%) were positive for Chlamydia spp.

218 PCR (113 at D0 and 105 at D2), 91 patients (87.5\%) were positive for Mycoplasma spp.
Anaplasma spp. and F. tularensis were not detected in this study.

17 PCRs, in 11 patients out of 33 tested (33\%) were positive for Theileria spp.

Day 0 (D0) versus day 2 (D2). Globally the results are similar between D0, D2 and D0 + D2. Individually, in 7 cases where real time PCR had isolated no micro-organisms at D0, the second analysis found microorganisms. In some cases, the second analysis showed different microorganisms (Fig. 6) (Table 4).

\section{Matrices}

Venous blood was explored in 97 patients (97 at D0, 97 at D2), urine in 104 patients (104 at D0, 104 at D2), saliva in 104 patients (102 at D0, 101 at D2), and capillary blood in 


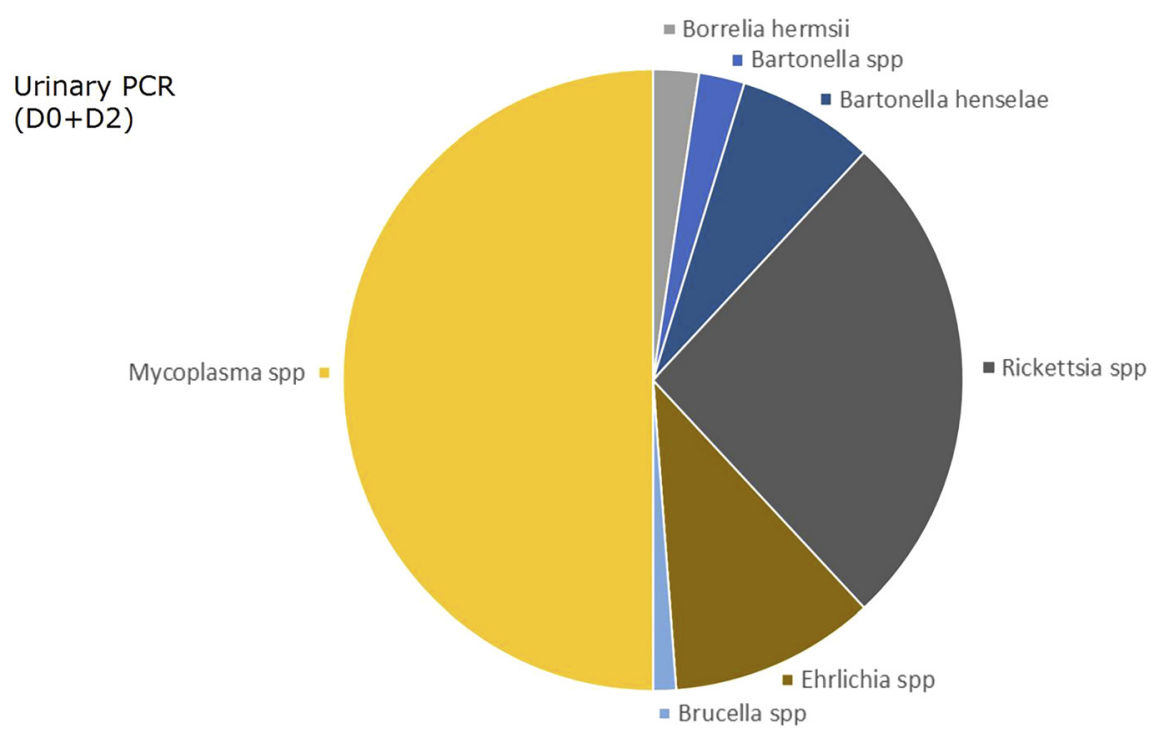

Fig. 3. Urinary PCR results at D0 + D2

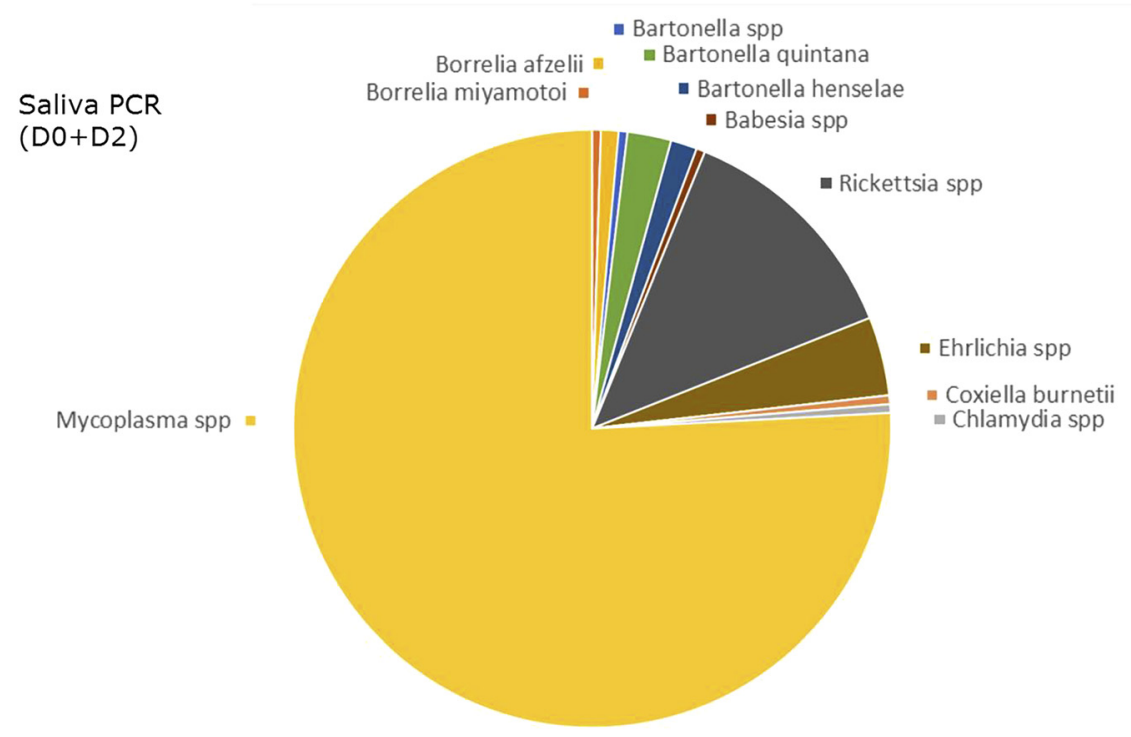

Fig. 4. Saliva PCR results at D0 $+\mathrm{D} 2$

only 65 patients (63 at D0, 62 at D2). For most patients, PCRs were studied twice, at D1 and D2: 97 of 97 from venous blood, 104 of 104 from urine, 100 of 104 from saliva and 62 of 65 from capillary blood.

Microorganisms found by matrix. In venous blood, the main microorganism found was Ehrlichia spp. (found 7 times out of a total of 23 positive results, $30.4 \%$ ) followed by Babesia spp. (found 6 times out of a total of 23 positive results, 26.1\%) (Fig. 2).

In urine, the main microorganism found was Mycoplasma spp. (found 42 times out of a total of 85 positive results, $49.4 \%$ ) followed by Rickettsia spp. (found 22 times out of a total of 85 positive results, 25.9\%) (Fig. 3).

In saliva, the main microorganism found was $\mathrm{Myco-}$ plasma spp. (found 160 times out of a total of 222 positive results, 72.7\%) followed by Rickettsia spp. (found 27 times out of a total of 222 positive results, 12.3\%) (Fig. 4).

In capillary blood, the main microorganism found was Mycoplasma spp. (found 15 times out of a total of 38 positive results, 39.5\%) followed by Babesia spp. (found 7 times out of a total of 38 positive results, 18.4\%) (Fig. 5).

Matrix performance - overall results. Percentage analyses were performed by weighting the results according to the number of analyses performed for each matrix.

Overall, the most informative matrix was saliva (42.08\%), followed by urine $(27.95 \%)$, capillary blood $(18.23 \%)$, and venous blood (11.73\%) (Fig. 7).

Matrix performance - results by microorganism. The results per microorganism (pathogen-specific PCR sequences) 


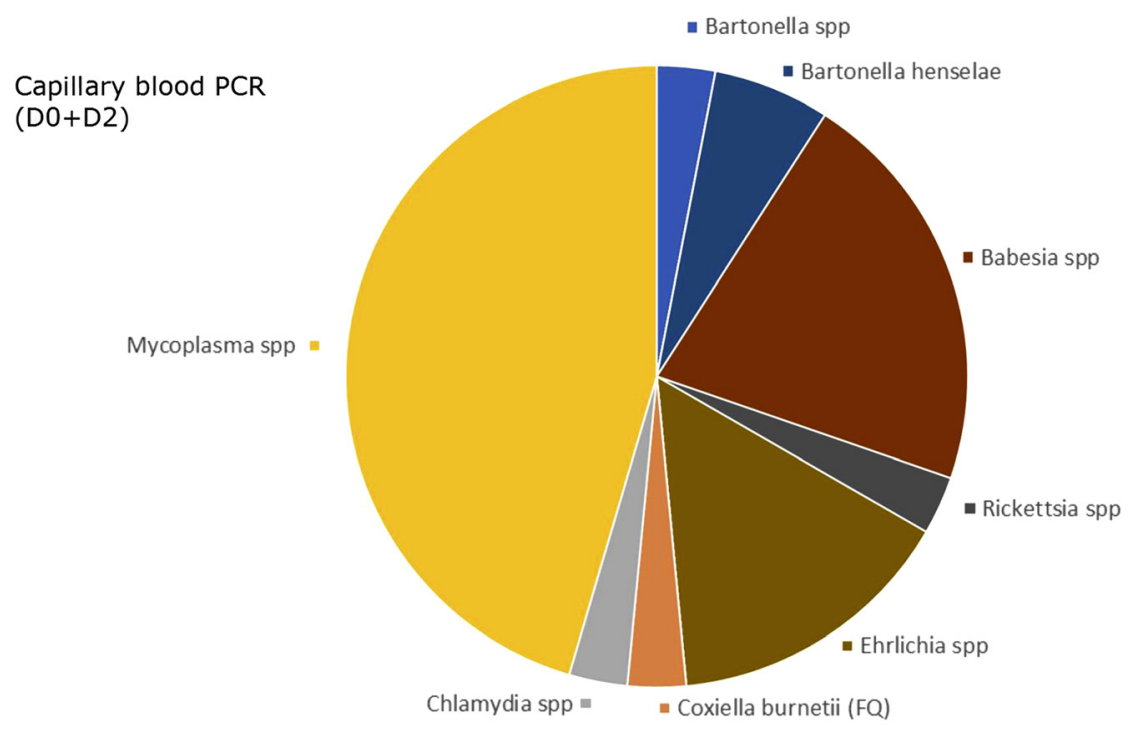

Fig. 5. Capillary blood PCR results at D0 + D2

Repartition of the microorganisms found at D0, D2 and D0+D2

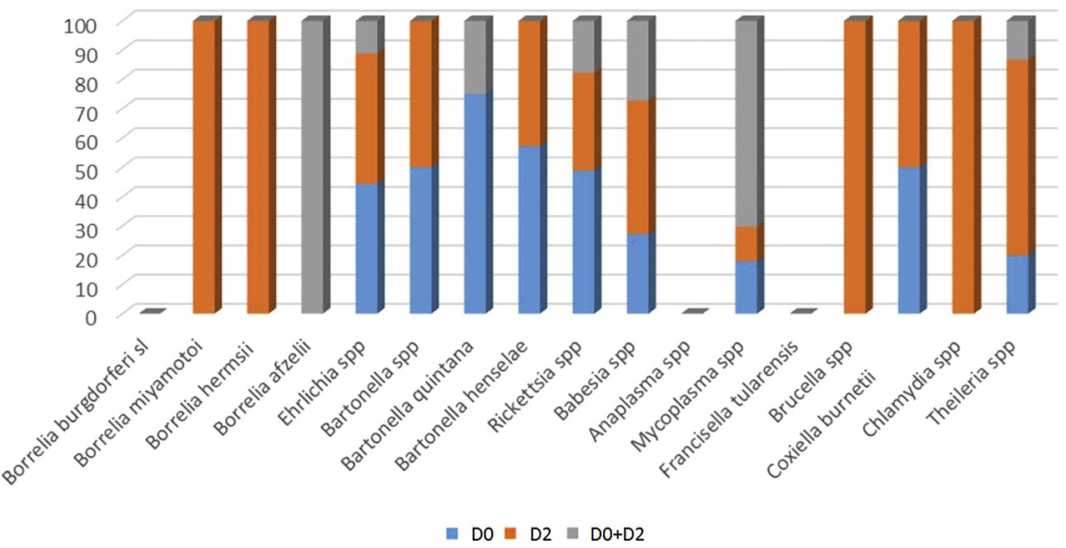

Fig. 6. Distribution of the microorganisms at D0, D2 and D0+D2

are weighted in relation to the number of analyses performed for each matrix.

Mycoplasma spp. were the most frequently identified micro-organisms. Mycoplasma spp. were found mainly in saliva. In this "open" environment, it is possible to hypothesize commensal microorganisms. Mycoplasma spp. were found once in venous blood (0.5\%), 15 times in capillary blood (10.6\%), 42 times in urine (18.5\%) and 160 times in saliva $(70.5 \%)$.

For Borrelia, the two informative matrices were urine (50\%) and saliva (50\%).

Bartonella spp. were found in all 4 matrices: B. quintana was found 5 times in saliva $(100 \%)$. B. henselae was found twice in venous blood (14.9\%), twice in capillary blood (22.3\%), 6 times in urine (41.8\%) and thrice in saliva (20.9\%).

Bartonella spp. were found once in venous blood $(18.9 \%)$, once in capillary blood $(28.2 \%)$, twice in urine $(35.3 \%)$ and once in saliva (17.6\%).
Babesia spp. were found 6 times in venous blood (34.5\%), 7 times in capillary blood (60.1\%), 0 time in urine and once in saliva (5.4\%).

Rickettsia spp. were found thrice in venous blood (6\%), once in capillary blood (3\%), 22 times in urine (40.9\%) and 27 times in saliva (50.2\%).

C. burnetii was found thrice in venous blood (55.3\%), once in capillary blood (27.5\%), 0 time in urine, and once in saliva (17.2\%).

Ehrlichia spp. was found 7 times in venous blood (22.4\%), 5 times in capillary blood (23.9\%), 9 times in urine (26.9\%), and 9 times in saliva (26.9\%).

Brucella was found once in urine.

Chlamydia spp. was found once in capillary blood $(61.5 \%)$, once in saliva $(38.5 \%)$.

Theileria spp. were searched for in only 33 patients and found 17 times in total, 5 times in capillary blood (29.4\%), once in urine $(5.9 \%)$ and 11 times in saliva (64.7\%). 
Table 4. PCRs results

\begin{tabular}{|c|c|c|c|c|c|c|c|c|}
\hline & \multirow[b]{2}{*}{ D0 } & \multirow[b]{2}{*}{ D2 } & \multirow[b]{2}{*}{$\mathrm{D} 0+\mathrm{D} 2$} & \multicolumn{4}{|c|}{$\mathrm{D} 0+\mathrm{D} 2$} & \multirow[b]{2}{*}{ Patients } \\
\hline & & & & Blood & Urine & Saliva & Capillary blood & \\
\hline Borrelia burgdorferi s.l. & 0 & 0 & 0 & 0 & 0 & 0 & 0 & $0 / 104(0 \%)$ \\
\hline Borrelia miyamotoi & 0 & 1 & 1 & 0 & 0 & 1 & 0 & $1 / 104(0.96 \%)$ \\
\hline Borrelia afzelii & 1 & 1 & 2 & 0 & 0 & 2 & 0 & $1 / 104(0.96 \%)$ \\
\hline Borrelia hermsii & 0 & 2 & 2 & 0 & 2 & 0 & 0 & $2 / 104(1.92 \%)$ \\
\hline Ehrlichia spp. & 15 & 15 & 30 & 7 & 9 & 9 & 5 & $15 / 104(14.42 \%)$ \\
\hline Bartonella spp. & 3 & 2 & 5 & 1 & 2 & 1 & 1 & $4 / 104(3.85 \%)$ \\
\hline Bartonella quintana & 4 & 1 & 5 & 0 & 0 & 5 & 0 & $4 / 104(3.85 \%)$ \\
\hline Bartonella henselae & 7 & 6 & 13 & 2 & 6 & 3 & 2 & $8 / 104(7.7 \%)$ \\
\hline Rickettsia spp. & 30 & 23 & 53 & 3 & 22 & 27 & 1 & $31 / 104(29.8 \%)$ \\
\hline Babesia spp. & 6 & 8 & 14 & 6 & 0 & 1 & 7 & 9/104 (8.65\%) \\
\hline Anaplasma spp. & 0 & 0 & 0 & 0 & 0 & 0 & 0 & $0 / 104(0 \%)$ \\
\hline Francisella tularensis & 0 & 0 & 0 & 0 & 0 & 0 & 0 & $0 / 104(0 \%)$ \\
\hline Brucella spp. & 0 & 1 & 1 & 0 & 1 & 0 & 0 & $1 / 104(0.96 \%)$ \\
\hline Coxiella burnetii & 3 & 2 & 5 & 3 & 0 & 1 & 1 & $3 / 104(2.88 \%)$ \\
\hline Chlamydia spp. & 0 & 2 & 2 & 0 & 0 & 1 & 1 & $2 / 104(1.92 \%)$ \\
\hline Theileria spp. & 5 & 12 & 17 & 0 & 1 & 11 & 5 & $11 / 33(33.3 \%)$ \\
\hline Mycoplasma spp. & 113 & 105 & 218 & 1 & 42 & 160 & 15 & $91 / 104(87.5 \%)$ \\
\hline
\end{tabular}

Spp.: species plurimae (all species in the genus).

\section{Contribution of each matrix}

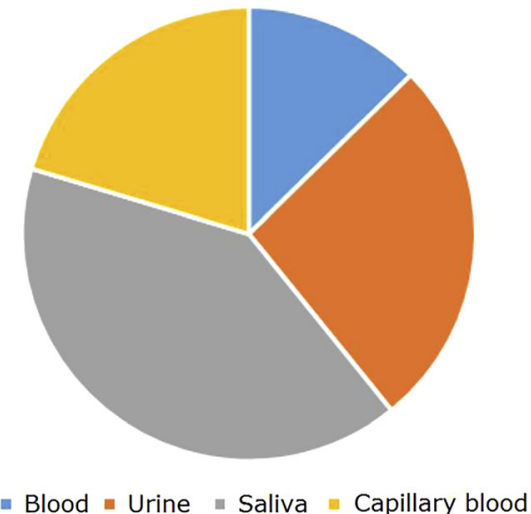

\section{Contribution of each matrix without Mycoplasma spp}

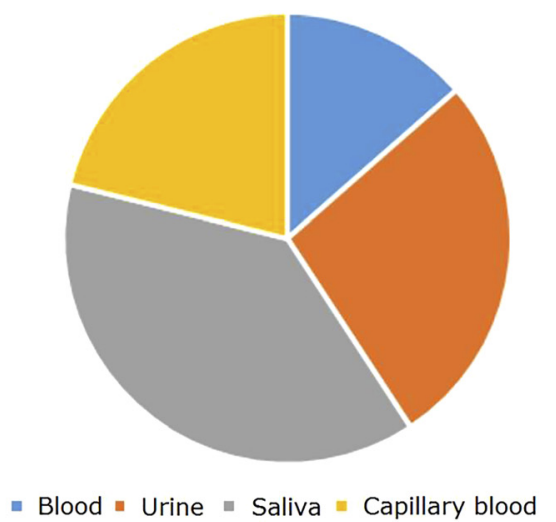

Fig. 7. Overall contribution of matrices with and without Mycoplasma spp.

For a given patient, microorganisms were most often found in one matrix only $(67.4 \%)$, then in two matrices (25\%), three matrices (6\%), and finally four matrices (1.6\%).

Ehrlihia spp. and B. henselae were the only microorganisms observed in all 4 matrices, once and twice, respectively (Table 5).

\section{Poly-infection}

Among the 104 patients who had a complete analysis (at D0 and D2), no microorganisms were found in 5 patients (4.81\%), only one microorganism in 49 patients $(47.12 \%)$, two different microorganisms in 25 patients $(24.04 \%)$, three or more microorganisms in 25 patients (24.04\%) (Figs 8 and 9) (Table 6). Thus, $48 \%$ of patients were poly-infected. The same analysis was performed without taking into account Mycoplasma spp., that could be considered as commensal bacteria. In this analysis, no microorganisms were found in 48 patients
(46.15\%), one single microorganism in 30 patients $(28.85 \%)$, two different microorganisms in 16 patients $(15.38 \%)$, three or more microorganisms in 10 patients (9.62\%) Excluding Mycoplasma spp., $26 \%$ of patients were poly-infected.

\section{DISCUSSION}

This study showed that most patients with a combination of signs and symptoms consistent with the diagnosis of SPPT/ PTLDS harbour microorganisms that are well detected using real time qPCR. As a matter of fact, Borrelia spp. were not the most frequent bacteria, observed far behind Mycoplasma spp., Rickettsia spp. and Ehrlichia spp. which were the most frequent microorganisms identified (Fig. 1). It could be hypothesized that the frequency of Borrelia is lower than expected or that this bacterium is particularly difficult to detect. 
Table 5. Number of positive matrices per microorganism for a given patient

\begin{tabular}{|c|c|c|c|c|c|}
\hline & $\begin{array}{l}\text { Detected in } 1 \\
\text { matrix }\end{array}$ & $\begin{array}{c}\text { Detected in } 2 \\
\text { matrices }\end{array}$ & $\begin{array}{c}\text { Detected in } 3 \\
\text { matrices }\end{array}$ & $\begin{array}{c}\text { Detected in } 4 \\
\text { matrices }\end{array}$ & $\begin{array}{c}\text { Number of patients } \\
+\end{array}$ \\
\hline Borrelia burgdorferi s.l. & & & & & 0 \\
\hline Borrelia miyamotoi & 1 & & & & 1 \\
\hline Borrelia afzelii & 1 & & & & 1 \\
\hline Borrelia hermsii & 2 & & & & 2 \\
\hline Ehrlichia spp. & 9 & 3 & 1 & 2 & 15 \\
\hline Bartonella spp. & 4 & & & & 4 \\
\hline Bartonella quintana & 4 & & & & 4 \\
\hline Bartonella henselae & 4 & 1 & 1 & 1 & 8 \\
\hline Rickettsia spp. & 22 & 10 & & & 31 \\
\hline Babesia spp. & 9 & 1 & & & 9 \\
\hline Anaplasma spp. & & & & & 0 \\
\hline Francisella tularensis & & & & & 0 \\
\hline Brucella spp. & 1 & & & & 1 \\
\hline Coxiella burnetii & 2 & 1 & & & 3 \\
\hline Chlamydia spp. & 2 & & & & 2 \\
\hline Theileria spp. & 7 & 4 & & & 11 \\
\hline Mycoplasma spp. & 56 & 26 & 9 & & 91 \\
\hline
\end{tabular}

Spp.: species plurimae.

\section{Percentage of patient detected in relation to the number of the different microorganisms (m.o.) detected with Mycoplasma spp}

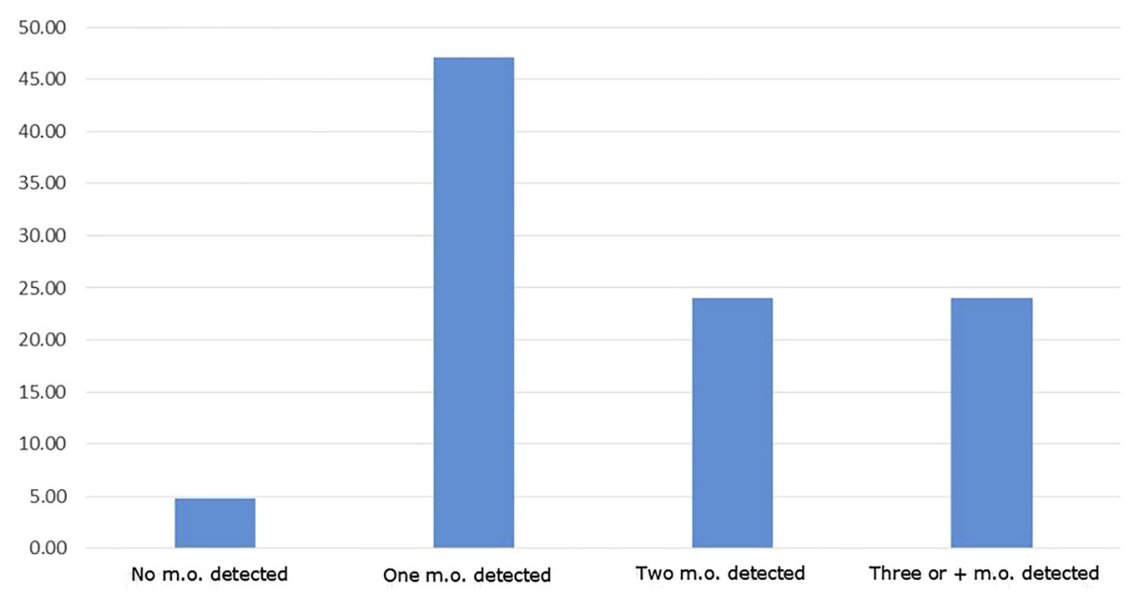

Fig. 8. Percentage of patients detected in relation to the number of the different microorganisms detected with Mycoplasma spp.

Borrelia could be present in deeper locations in a wide range of organs (brain for example) and thus could not be detected in this study, despite the use of several matrices [24].

In our study, piroplasms were found in a significant number of patients. Before this study, Theileria pathogenspecific PCR sequences, well known in veterinary medicine as it usually infests horses [25], were never isolated from humans. There is a very great genetic proximity between Babesia microti and Theileria microti and our PCR primers are studied to specifically isolate the genus Babesia from the genus Theileria. The fact that only Babesia species were known in human medicine is not an argument to say that theileriasis is not a human disease. A surprising result is that we isolated much more Theileria spp. than Babesia spp.
These preliminary results suggest that Theileria could be a significant pathogen for humans. These results should be confirmed by additional studies. Babesia are most commonly known to cause severe infection with shock, mainly in patients who have undergone splenectomy. However, some articles describe some authentic Babesia spp. infections in immunocompetent patients, sometimes recurrent, with a torpid, chronic presentation [26-28]. Babesiosis is in fact poorly known, and it is probable that the frequency of infection by these parasites is underestimated [29]. As previously suggested by Muriel Vayssier Taussat et al. [18], various species of Bartonella, including species which were only known in veterinary medicine, could be responsible for various persistent signs and symptoms in humans. In further 


\section{Percentage of patient detected in relation to the number of the different microorganisms (m.o.) detected without Mycoplasma spp}

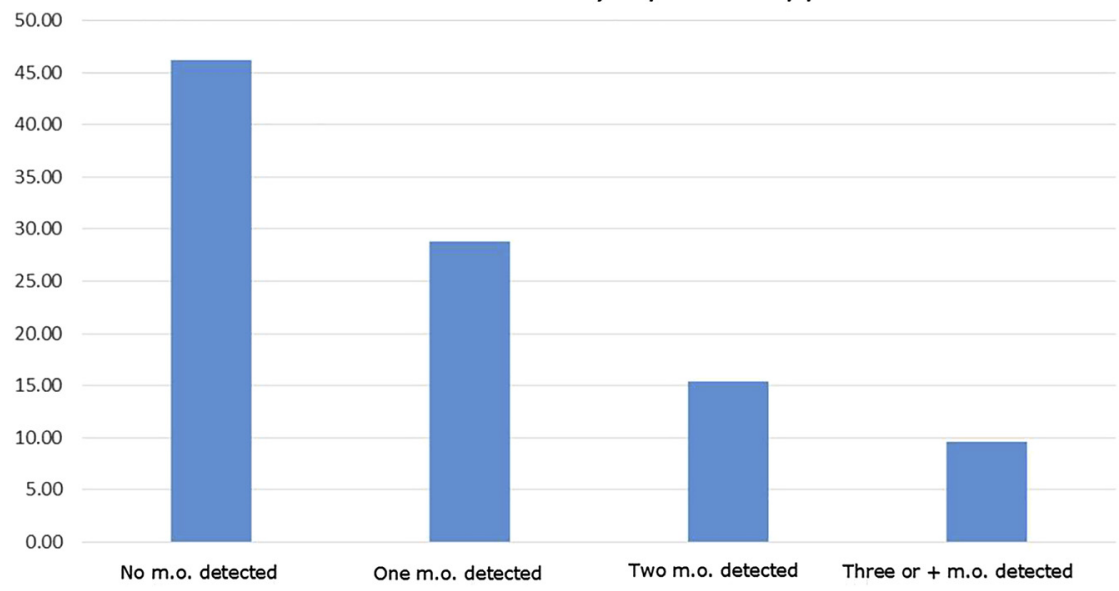

Fig. 9. Percentage of patients detected in relation to the number of the different microorganisms detected without Mycoplasma spp.

Table 6. Poly-infection: number of microorganisms detected per patient

\begin{tabular}{|c|c|c|c|c|c|}
\hline \multirow{2}{*}{$\begin{array}{l}\text { Number of microorganism(s) detected } \\
\text { per patient }\end{array}$} & \multicolumn{4}{|c|}{$\begin{array}{l}\text { Percentage of patients based on the number of different } \\
\text { microorganisms detected }\end{array}$} & \\
\hline & 0 & 1 & 2 & 3 and + & \\
\hline With Mycoplasma spp. & 4.81 & 47.12 & 24.04 & 24.04 & \\
\hline Without Mycoplasma spp. & 46.15 & 28.85 & 15.38 & 9.62 & \\
\hline & \multicolumn{4}{|c|}{ Number of patients } & \multirow[b]{2}{*}{ Total } \\
\hline $\begin{array}{l}\text { Number of microorganism(s) detected } \\
\text { per patient }\end{array}$ & 0 & 1 & 2 & 3 and + & \\
\hline With Mycoplasma spp. & 5 & 49 & 25 & 25 & 104 \\
\hline Without Mycoplasma spp. & 48 & 30 & 16 & 10 & 104 \\
\hline
\end{tabular}

Spp.: species plurimae.

studies, the identification of the Bartonella species should be an important goal. Some bacteria such as Mycoplasma spp. are not constantly transmitted by ticks and could be commensal bacteria. However, some mycoplasmas such as Mycoplasma fermentans can be transmitted by ticks and be pathogenic [30]. Furthermore, Lyme disease can lead to a depression of the immune system [31], resulting in the occurrence of opportunistic infections, which could include Mycoplasma infections. These microorganisms, in particular Mycoplasma, could be transmitted by other sources than the tick bite, for example by sexual contamination. It might be thus more accurate to change the paradigm, and consider the term "crypto-infections" rather than exclusively "tickborne infections" [32].

The study showed that nearly half of the patients were poly-infected, and a quarter of them harboured at least three different microorganisms. Indeed, at this preliminary stage of the research, it is not possible to distinguish between latent carriage and active infection.

The isolation of micro-organisms in saliva may be difficult to interpret. As the mouth is an open area, it could be a contamination from the outside. However, salivary secretion of micro-organisms exists. Some micro-organisms have a tropism for salivary glands, and the role of saliva for transmission of some infections, such as rabies or Epstein Barr virus, is well known. Salivary glands are holomerocrine. Secretion needs disruption of the apex of the acini cells. Thus, these acini cells must multiply rapidly. This could enhance the tropism of some micro-organisms. The possible secretion of micro-organisms by saliva should be further investigated. The results obtained from the different matrices provide interesting data.

For Mycoplasma, a high level of isolation from saliva and urine was observed. There was a trend for a superiority of capillary blood samples. For the Mycoplasma urine results, a possible contamination from the genital tract cannot be excluded. A precise characterization of the Mycoplasma species should be further studied. For Bartonella, urine samples seemed interesting. For Ehrlichia, the four matrices seemed interesting. For Rickettsia, a high level of isolation from saliva and urine was observed, without benefit from the capillary blood samples. For Coxiella, venous blood 
samples provided the best results with a small additional benefit when combining with capillary blood samples. The most astonishing results were the very low sensitivity for Borrelia. For Babesia isolation, it was better to combine venous and capillary blood samples. Thus, this study showed that venous blood was the less sensitive matrix, far behind saliva, urine and capillary blood. In our study, Borrelia was found a few times in urine and saliva, but not in the blood. This confirms data from previous studies that showed a low interest of venous blood PCR for the detection of Borrelia. In this setting, PCR sensitivities and specificities are heterogeneous [33]. Some studies used PCR to identify $B$. burgdorferi in early Lyme disease, while we studied it in a chronic stage $[34,35]$. In Eshoo et al.'s study, the sensitivity at an early stage was $62 \%$ and the specificity $100 \%$ [35]. Liveris et al. reported a sensitivity of $40.6 \%$ [34]. In these studies on early Lyme disease, the direct detection sensitivity was lower than that of the two-tier serology. However, in Bil-Lula's study, $3 \%$ of patients with negative ELISA IgM test, 2.8\% with negative Line blot IgM test, 3.1\% and $2.7 \%$ with negative ELISA IgG and Line blot IgG tests, respectively, were positive in real time PCR [20]. Few studies looked by PCR for Borrelia in urine. In one study, detection rate was $91 \%$ in patients with Lyme disease skin lesions [36]. In another study, results were disappointing [37].

Our study showed the advantage of a double sample for PCR at Day 0 and Day 2: individually, in 7 cases where real time PCR had isolated no micro-organisms at D0, the second analysis found microorganisms. In some cases, the second analysis showed different microorganisms. Therefore performing the PCR assays several times (in this case at D0 and D2), could increase the sensitivity of detection and improve the diagnosis of patient infections.

The clinical signs observed in SPPT/PTLDS may thus have an infectious origin (even if dysimmunitary phenomenons can play a role), and not a psychiatric origin as it has been previously hypothetised [38]. In our experience, the detection of bacteria and the presence of multiple co-infections often induce a more severe disease. However, our study was not designed to evaluate this specific point, which needs to be proven in future clinical studies. Most of our patients had a wide variety of clinical signs as follows: joint, muscle and tendon pain, neurological pain, tingling, sweats, hot flashes, fatigue, sleep difficulty, focusing/concentrating, neck pain, headache, difficulty finding words, irritability, low back pain, joint swelling, double vision, drooping facial muscle, drooping eyelid, tinnitus, heart palpitations. To confirm our results, subsequent studies showing that tickexposed, healthy individuals do not exhibit a similar infection rate are necessary. The evaluation of appropriate antiinfective treatments in these patients, and real time qPCR tests after treatment, is also needed.

SPPT/PTLDS is very similar and difficult to dissociate from fibromyalgia syndromes [22, 23, 39, 40]. These syndromes associate three major signs: disabling fatigue, neuropsychic disorders (memory, sleep, concentration disorders) and various somatic signs; pain remains a predominant symptom [22, 23].

As all patients, in opposition to the persons in the control group, suffered from signs and symptoms, it is possible that the isolated microorganisms were actually responsible for the disease, or at least a cofactor. However, further studies on large populations, including healthy control persons, should look at the possibility of asymptomatic carriage.

In conclusion, our prospective study has shown that patients with persistent polymorphic syndrome possibly due to a tick bite (SPPT)/post-treatment Lyme disease syndrome (PTLDS), a syndrome close to fibromyalgia, could harbour several tick borne microorganisms. Microbiologic analyses should not be limited to Borrelia's research alone. Taking several successive samples on different days could improve the detection of these microorganisms. Venous blood seems to be the less sensitive matrix, far behind saliva, urine and capillary blood. For some microorganisms, capillary blood seems to be more informative than venous blood. Thus, in the case of SPPT/PTLDS, qPCR analyses should be performed on different matrices to ensure optimal cost-effectiveness diagnostic. This study should be considered as a preliminary one. Due to the strong Lyme controversy, the absence of gold standards, the limited results published on co-infections identification, the low sensitivity of blood PCRs, it is difficult to rely on the literature to try to establish comparisons. Further studies are needed.

Key points: Our prospective real time qPCR (quantitative polymerase chain reaction) study has shown that patients with persistent polymorphic syndrome possibly due to a tick bite (SPPT)/post-treatment Lyme disease syndrome (PTLDS) could harbour several tick borne microorganisms.

Venous blood seems to be the less sensitive matrix, far behind saliva, urine and capillary blood.

The study showed that there was a benefit to performing the analyses twice, by increasing the detection of micro-organisms.

\section{Conflict of interest: Michel Franck is CEO of ADNucleis.}

The others authors do not declare any conflict of interest.

Funding: This work was supported by ELSAN group.

This work was supported by Rotary Club of Montfort l'Amaury - Houdan, France.

Authors' contributions: Alexis Lacout: Conceptualization, Writing original draft, Funding Acquisition.

Marie Mas: Conceptualization, Investigation.

Julie Pajaud: Writing, review and editing, Resources.

Véronique Perronne: Writing original draft.

Yannick Lequette: Writing, review and editing.

Michel Franck: Investigation, Writing, review and editing, Resources, Validation.

Christian Perronne: Writing, review and editing; Supervision. 


\section{REFERENCES}

1. https://www.hhs.gov/ash/advisory-committees/tickbornedisease/ meetings/2018-07-24/meeting-summary/index.html?language $=\mathrm{es}$

2. Alby K, Capraro GA. Alternatives to serologic testing for diagnosis of Lyme disease. Clin Lab Med 2015; 35: 815-25.

3. Cook MJ, Puri BK. Commercial test kits for detection of Lyme borreliosis: a meta-analysis of test accuracy. Int J Gen Med 2016; 9: 427-40.

4. Leeflang M.M., et al. The diagnostic accuracy of serological tests for Lyme borreliosis in Europe: a systematic review and meta-analysis. BMC Infect Dis 2016; 16: 140.

5. Rapport d'activité du Haut conseil de la Santé publique HSCP. High Council for Public Health, (in French). (March 2014). https:// www.hcsp.fr/explore.cgi/dra2014.pdf/.

6. Schutzer SE, Coyle PK, Belman AL, Golightly MG, Drulle J. Sequestration of antibody to Borrelia burgdorferi in immune complexes in seronegative Lyme disease. Lancet 1990; 335: 312-5.

7. Horowitz RI, Lacout A, Marcy PY, Perronne C. To test or not to test? Laboratory support for the diagnosis of Lyme borreliosis. Clin Microbiol Infect 2018;24(2):210.

8. Perronne C, Lacout A, Marcy PY, El Hajjam M. Errancy on Lyme diagnosis. Am J Med 2017; 130(5): e219.

9. Cisak E, Wójcik-Fatla A, Zając V, Dutkiewicz J. Prevalence of tickborne pathogens at various workplaces in forest exploitation environment. Med Pr 2014; 65(5): 575-81.

10. Sanchez-Vicente S, Tagliafierro T, Coleman JL, Benach JL, Tokarz R. Polymicrobial nature of tick-borne diseases. mBio 2019 Sep 10; 10(5): e02055-19. https://doi.org/10.1128/mBio.02055-19.

11. Michelet L, Delannoy S, Devillers E, Umhang G, Aspan A, Juremalm M, et al. High-throughput screening of tick-borne pathogens in Europe. Front Cell Infect Microbiol 2014 Jul 29; 4: 103.

12. Nelder MP, Russell CB, Sheehan NJ, Sander B, Moore S, Li Y, et al. Human pathogens associated with the blacklegged tick Ixodes scapularis: a systematic review. Parasit Vectors 2016 May 5; 9: 265. https://doi.org/10.1186/s13071-016-1529-y.

13. Franck M, Ghozzi R, Pajaud J, Lawson-Hogban NE, Mas M, Lacout A, et al. Borrelia miyamotoi: 43 cases diagnosed in France by realtime PCR in patients with persistent polymorphic signs and symptoms. Front Med (Lausanne) 2020 Feb 28; 7: 55. PMID: 32181254; PMCID: PMC7059645. https://doi.org/10.3389/fmed. 2020.00055.

14. Platonov AE, Karan LS, Kolyasnikova NM, Makhneva NA, Toporkova MG, Maleev VV, et al. Humans infected with relapsing fever spirochete Borrelia miyamotoi, Russia. Emerg Infect Dis 2011 Oct; 17(10): 1816-23. PMID: 22000350; PMCID: PMC3310649. https:// doi.org/10.3201/eid1710.101474.

15. Maggi RG, Mozayeni BR, Pultorak EL, Hegarty BC, Bradley JM, Correa $\mathrm{M}$, et al. Bartonella spp. bacteremia and rheumatic symptoms in patients from Lyme disease-endemic region. Emerg Infect Dis 2012 May;18(5):783-91. Available from: https://doi.org/ 10.3201/eid1805.111366.

16. Berghoff W. Chronic Lyme disease and Co-infections: differential diagnosis. Open Neurol J 2012; 6: 158-78. Epub 2012 Dec 28. https://doi.org/10.2174/1874205X01206010158.

17. Breitschwerdt EB, Maggi RG, Nicholson WL, Cherry NA, Woods CW. Bartonella Sp. Bacteremia in patients with neurological and neurocognitive dysfunction. J Clin Microbiol 2008 Sep; 4616(9): 2856-61. Epub 2008 Jul. https://doi.org/10.1128/JCM.00832-08.

18. Vayssier-Taussat M, Moutailler S, Féménia F, Raymond P, Croce O, La Scola B, et al. Identification of novel zoonotic activity of Bartonella spp., France. Emerg Infect Dis 2016 Mar; 22(3): 457-62. PMID: 26885624; PMCID: PMC4766919. https://doi.org/ 10.3201/eid2203.150269.

19. Feder HM, Jr, Johnson BJ, O'Connell S, Shapiro ED, Steere AC, Wormser GP, Ad Hoc International Lyme Disease Group, et al. A critical appraisal of "chronic Lyme disease". N Engl J Med 2007 Oct 4; 357(14): 1422-30. Erratum in: N Engl J Med. 2008 Mar 6; 358(10): 1084. https://doi.org/10.1056/NEJMra072023.

20. Bil-Lula I, Matuszek P, Pfeiffer T, Woźniak M. Lyme borreliosis-the utility of improved real-time PCR assay in the detection of Borrelia burgdorferi infections. Adv Clin Exp Med 2015; 24: 663-70.

21. Ružić-Sabljić E, Cerar T. Progress in the molecular diagnosis of Lyme disease. Expert Rev Mol Diagn 2017 Jan; 17(1): 19-30. Epub 2016 Nov 28. PMID: 27892737. https://doi.org/10.1080/14737159. 2016.1246959.

22. Aucott JN. Posttreatment Lyme disease syndrome. Infect Dis Clin North Am 2015 Jun;29(2):309-23. Available from: https://doi.org/ 10.1016/j.idc.2015.02.012.

23. Haute Autorité de Santé (High Authority for Health). Recommandation de bonne pratique. Borréliose de Lyme et autres maladies vectorielles à tiques (MVT). (in French); June 2018. https:// www.has-sante.fr/upload/docs/application/pdf/2018-06/reco266_ rbp_borreliose_de_lyme_cd_2018_06_13_recommandations.pdf.

24. Häupl T, Hahn G, Rittig M, Krause A, Schoerner C, Schönherr U, et al. Persistence of Borrelia burgdorferi in ligamentous tissue from a patient with chronic Lyme borreliosis. Arthritis Rheum 1993 Nov; 36(11):1621-6.

25. Onyiche TE, Suganuma K, Igarashi I, Yokoyama N, Xuan X, Thekisoe O. A review on equine piroplasmosis: epidemiology, vector ecology, risk factors, host immunity, diagnosis and control. Int J Environ Res Public Health 2019 May 16; 16(10): pii: E1736. https://doi.org/10.3390/ijerph16101736.

26. Vannier E, Gewurz BE, Krause PJ. Human babesiosis. Infect Dis Clin North Am 2008 Sep; 22(3): 469-88. viii-ix. https://doi.org/10. 1016/j.idc.2008.03.010.

27. Krause PJ. Human babesiosis. Int J Parasitol 2019 Feb; 49(2): 165-74. Epub 2019 Jan 26. https://doi.org/10.1016/j.ijpara.2018.11.007.

28. Krause PJ, Spielman A, Telford SR, 3rd, Sikand VK, McKay K, Christianson D, et al. Persistent parasitemia after acute babesiosis. N Engl J Med 1998 Jul 16; 339(3): 160-5.

29. Martinot M, Paleau A, Greigert V, Brunet J, Hansmann Y, Jouglin $\mathrm{M}$, et al Babésiose en France et en Europe : une pathologie à redéfinir. Med Mal Inf June 2018; 48(4): S112. Supplement.

30. Eskow E, Adelson ME, Rao RV, Mordechai E. Evidence for disseminated Mycoplasma fermentans in New Jersey residents with antecedent tick attachment and subsequent musculoskeletal symptoms. J Clin Rheumatol 2003 Apr; 9(2): 77-87.

31. Elsner RA, Hastey CJ, Olsen KJ, Baumgarth N. Suppression of longlived humoral immunity following Borrelia burgdorferi infection. Plos Pathog 2015 Jul 2; 11(7): e1004976. eCollection 2015 Jul. https://doi.org/10.1371/journal.ppat.1004976.

32. Perronne C. Crypto-infections: denial, censorship and suppression the truth about what lies behind. Hammersmith Health Books; 2021. 
33. Waddell LA, Greig J, Mascarenhas M, Harding S, Lindsay R, Ogden $\mathrm{N}$. The accuracy of diagnostic tests for Lyme disease in humans, A systematic review and meta-analysis of north American research. PLoS One 2016 Dec 21; 11(12): e0168613. eCollection 2016. https:// doi.org/10.1371/journal.pone.0168613.

34. Liveris D, Schwarz I, McKenna D, Nowakowski J, Nadelman R, Demarco J, et al. Comparison of five diagnostic modalities for direct detection of Borrelia burgdorferi in patients with early Lyme disease. Diagn Microbiol Infect Dis 2012; 73: 243-5. PMID: 22571973. https://doi.org/10.1016/j.diagmicrobio.2012.03.026.

35. Eshoo MW, Crowder CC, Rebman AW, Rounds MA, Matthews HE, Picuri JM, et al. Direct molecular detection and genotyping of Borrelia burgdorferi from whole blood of patients with early Lyme disease. PLoS One 2012; 7: e36825. PMID: 22590620. https://doi. org/10.1371/journal.pone.0036825.

36. Schmidt BL, Aberer E, Stockenhuber C, Klade H, Breier F, Luger A. Detection of Borrelia burgdorferi DNA by polymerase chain reaction in the urine and breast milk of patients with
Lyme borreliosis. Diagn Microbiol Infect Dis 1995 Mar; 21(3): 121-8.

37. Rauter C, Mueller M, Diterich I, Zeller S, Hassler D, Meergans T, Hartung T. Critical evaluation of urine-based PCR assay for diagnosis of Lyme borreliosis. Clin Diagn Lab Immunol 2005 Aug;12(8):910-7.

38. Kennedy AG. Differential diagnosis and the suspension of judgment. J Med Philos 2013 Oct; 38(5): 487-500. Epub 2013 Aug 29. https://doi.org/10.1093/jmp/jht043.

39. Wolfe F, Clauw DJ, Fitzcharles MA, Goldenberg DL, Katz RS, Mease P, Russell AS, Russell IJ, Winfield JB, Yunus MB. The American College of Rheumatology preliminary diagnostic criteria for fibromyalgia and measurement of symptom severity. Arthritis Care Res (Hoboken) 2010 May;62(5):600-10. Available from: https://doi.org/10.1002/acr.20140.

40. Rebman AW, Bechtold KT, Yang T, Mihm EA, Soloski MJ, Novak $\mathrm{CB}$, Aucott JN. The clinical, symptom, and quality-of-life characterization of a well-defined group of patients with posttreatment Lyme disease syndrome. Front Med (Lausanne) 2017 Dec 14; 4: 224. 